DOI: http://dx.doi.org/10.18203/2320-1770.ijrcog20191219

Original Research Article

\title{
Assessment of maternal and fetal outcome in trial of labor after cesarean
}

\author{
Sunita Kumari Beer*, Jaya Choudhary, Kalpana Tiwari, Sonam Choudhary
}

Department of Obstetrics and Gynecology, Mahatma Gandhi Medical College and Hospital, Jaipur, Rajasthan, India

Received: 24 January 2019

Accepted: 05 March 2019

\section{*Correspondence:}

Dr. Sunita Kumari Beer,

E-mail: sunitadhaker09@gmail.com

Copyright: (C) the author(s), publisher and licensee Medip Academy. This is an open-access article distributed under the terms of the Creative Commons Attribution Non-Commercial License, which permits unrestricted non-commercial use, distribution, and reproduction in any medium, provided the original work is properly cited.

\begin{abstract}
Background: Nowadays, cesarean sections are increasing consistently. Repeat cesarean sections are performed for a large percentage and associated with a higher rate of surgical complications and Long-term morbidities. The trial of labor after cesarean offers an alternative choice. This study carried out to assess the maternal and fetal outcome and to evaluate various parameters as a predictor of success of TOLAC.

Methods: This prospective observational study conducted on 150 pregnant women with one previous LSCS who delivered at Mahatma Gandhi hospital, from January 2017 to July 2018. Patient having a singleton pregnancy, cephalic presentation, adequate pelvis size with spontaneous onset of labor were included. Cases were monitored carefully during the labor. Emergency LSCS was done if any indication appeared.

Results: $78 \%$ of cases delivered safely by the vaginal birth and $22 \%$ of cases had an emergency repeat cesarean section (EmRCS). Favorable Bishop Score, active stage of labor and prior vaginal delivery were associated with higher success rate. One $(0.66 \%)$ case of uterine scar rupture and $2(1.33 \%)$ cases of scar dehiscence noted. No maternal mortality observed. Perinatal mortality occurred in 2 cases $(1.33 \%)$.

Conclusions: Present study shows that appropriate clinical settings and the properly selected group of patients can make the TOLAC safe and effective.
\end{abstract}

Keywords: Emergency repeat cesarean section, Trial of labor after cesarean, Uterine scar rupture, Vaginal birth after cesarean

\section{INTRODUCTION}

The rate of cesarean section has increased sudden and strikingly all over the world during the past decades-from $5 \%$ in 1970 to $31.9 \%$ in $2016 .^{1}$ Main reasons for this rising rate are dependence on electronic fetal monitoring and decreasing expert skill in operative vaginal deliveries and fear of litigation. ${ }^{1,2}$

Repeated cesarean deliveries are performed for a large percentage $(56.6 \%)$, are associated with a higher rate of surgical complications and Long-term morbidities than VBAC. ${ }^{3-5}$ TOLAC offers an alternative choice to repeat cesarean section and is expected to fulfill a patient's desire for vaginal delivery and also it is associated with decreased maternal morbidity and lowering the risk of complications in subsequent pregnancies and lessens the overall cesarean rate.

The incidence of uterine scar rupture in TOLAC is very low $(0.5 \%-0.9 \%)$ in a previous transverse lower uterine incision. ${ }^{1}$ Proper assessment and monitoring of the TOLAC cases are required during the trial of labor.

The aim and objectives of this study were to assess the maternal and fetal outcome in TOLAC; to evaluate 
various parameters as a predictor of success of TOLAC and to study the safety and success of TOLAC.

\section{METHODS}

This prospective observational study carried out at Mahatma Gandhi medical college and hospital, Jaipur, over a period of one and a half year, after approval of the institutional ethical committee. After case selection, their written and informed consent was taken and they were explained about the need for emergency LSCS anytime during the trial of labor.

A detailed clinical history and antenatal examination were done. Hematological, serological investigation and USG for fetal well-being were done during antenatal visits and repeated during labor if required. Cases were monitored carefully during the labor for scar tenderness and continuous electronic fetal monitoring was done.

Partograph was plotted and four hourly per vaginal examination was done to assess the progress of labor done. Emergency LSCS was done if fetal distress or scar tenderness appeared or when the progress of labor was unsatisfactory.

\section{Inclusion criteria}

- A total of 150 women having a singleton pregnancy, cephalic presentation, adequate size of the pelvis, spontaneous onset of labor with one previous LSCS, were selected.

\section{Exclusion criteria}

- Cases with previous classical cesarean, previous two or more LSCS, any recurring indication for previous LSCS, any medical complication, were excluded from the study.

\section{RESULTS}

Table 1 shows out of 150 cases, 117 (78\%) cases delivered vaginally and $33(22 \%)$ cases ended up in emergency repeat cesarean section (EmRCS).

Table 1: Labor outcome of TOLAC in present study.

\begin{tabular}{|l|l|l|}
\hline Labor outcome & No. of cases (n) & Percentage \\
\hline VBAC & 117 & 78.00 \\
\hline EmRCS & 33 & 22.00 \\
\hline Total & 150 & 100.00 \\
\hline
\end{tabular}

Table 2 shows maximum number of the cases $105(70 \%)$ were with the favorable Bishop Score $\geq 6$, out of which 87 $(82.86 \%)$ cases delivered vaginally and $18(17.14 \%)$ cases had EmRCS. On applying the Chi-square test, the correlation was found statistically significant $(\mathrm{P}<0.05)$.
Table 2: Bishop's score on admission and labor outcome of TOLAC.

\begin{tabular}{|l|l|l|l|}
\hline $\begin{array}{l}\text { Bishop's } \\
\text { score }\end{array}$ & VBAC & EmRCS & Total \\
\hline$<6$ & $30(66.67)$ & $15(33.33)$ & $45(30.00)$ \\
\hline$\geq 6$ & $87(82.86)$ & $18(17.14)$ & $105(70.00)$ \\
\hline Total & $117(78.00)$ & $33(22.00)$ & $150(100.00)$ \\
\hline
\end{tabular}

Table 3 shows 114 (76\%) cases had no previous vaginal delivery and $36(24 \%)$ cases had a previous vaginal delivery (before or after CS). In this study population, the group with the history of previous vaginal delivery achieved a VBAC rate of $91.67 \%$ (33/36), as compared to $73.69 \%$ (84/114) in the group with no previous vaginal delivery. On applying the Chi-square test, the statistically significant association was found between prior vaginal delivery and success of TOLAC $(\mathrm{P}<0.05)$.

Table 3: Prior vaginal delivery and labor outcome of TOLAC.

\begin{tabular}{|l|l|l|l|}
\hline $\begin{array}{l}\text { Prior vaginal } \\
\text { delivery }\end{array}$ & VBAC & EmRCS & Total \\
\hline Yes & $33(91.67)$ & $\mathbf{n}(\mathbf{\%})$ & $\mathbf{n}(\mathbf{\%})$ \\
\hline No & $84(73.69)$ & $30(26.31)$ & $36(24.00)$ \\
\hline Total & $117(78.00)$ & $33(22.00)$ & $150(100.00)$ \\
\hline
\end{tabular}

In Table 4, the most common indication for EmRCS was non-progress of labor $(36.36 \%)$ and scar tenderness $(36.36 \%)$, followed by other indication as fetal distress $(21.21 \%)$ and arrest of the 2 nd stage of labor $(6.06 \%)$.

Table 4: Indication of EmRCS.

\begin{tabular}{|l|l|}
\hline Indication of EmRCS & EmRCS \\
\hline Non-progress of labor & $\mathbf{n}(\mathbf{\%})$ \\
\hline Scar tenderness & $12(36.36)$ \\
\hline Fetal distress & $12(36.36)$ \\
\hline An arrest of the $2^{\text {nd }}$ stage of labor & $7(21.21)$ \\
\hline Total & $2(6.06)$ \\
\hline
\end{tabular}

Table 5 shows, no complications were found in a maximum number of cases 135 (90\%). No complications occurred in 109 of VBAC and 26 of EmRCS cases. Out of $15(10 \%)$ cases with complications, 8 cases were of VBAC group and 7 cases were of EmRCS group, the majority of them managed conservatively.

Table 6 shows the maximum number of the neonates 125 $(83.33 \%)$ were in the $2.5-3.99 \mathrm{~kg}$ birth weight group. The $2.5-3.99 \mathrm{~kg},<2.5 \mathrm{~kg} ; \geq 4 \mathrm{~kg}$ birth weight group had VBAC in $93(74.40 \%)$ neonates, $20(95.24 \%)$ neonates and 4 $(100 \%)$ neonates respectively.

On applying the Chi-square test, the correlation was found statistically significant $(\mathrm{P}=0.05)$. 
Table 5: Distributions of TOLAC cases according to complications.

\begin{tabular}{|l|l|l|}
\hline Complications & VBAC & EmRCS \\
\hline None & $109(93.16)$ & $\mathbf{n}(\mathbf{\%})$ \\
\hline Atonic PPH & $3(2.57)$ & $2(6.06)$ \\
\hline Cervical tear & $3(2.57)$ & $1(3.03)$ \\
\hline Hematoma & $1(0.85)$ & $2(6.06)$ \\
\hline MRP for adherent placenta & $1(0.85)$ & $2(6.06)$ \\
\hline Total & $117(78.00)$ & $33(22.00)$ \\
\hline
\end{tabular}

Table 6: Baby birth weight and labor outcome of TOLAC.

\begin{tabular}{|l|l|l|l|}
\hline $\begin{array}{l}\text { Birth } \\
\text { weight }\end{array}$ & VBAC & EmRCS & Total \\
\hline$<2.5 \mathrm{~kg}$ & $20(95.24)$ & $\mathbf{n}(\mathbf{\%})$ & $\mathbf{n}(\mathbf{\%})$ \\
\hline $2.5-3.99 \mathrm{~kg}$ & $93(74.40)$ & $32(25.60)$ & $21(14.00)$ \\
\hline$\geq 4 \mathrm{~kg}$ & $4(100.00)$ & $0(0.00)$ & $4(2.67)$ \\
\hline Total & $117(78.00)$ & $33(22.00)$ & $150(100.00)$ \\
\hline
\end{tabular}

In the present study, authors recorded the Apgar score at 1 minute and 5 minutes after delivery to evaluate the neonatal outcome in all TOLAC cases.

Table 7: Labor outcome of TOLAC and Apgar score at 1 minute.

\begin{tabular}{|l|l|l|l|}
\hline $\begin{array}{l}\text { Apgar score at } \\
\mathbf{1} \text { min. }\end{array}$ & $\mathbf{n}(\mathbf{\%})$ & $\mathbf{n} \mathbf{( \% )}$ & $\mathbf{n}(\boldsymbol{\%})$ \\
\hline$\leq 7$ & $10(50.00)$ & $10(50.00)$ & $20(13.33)$ \\
\hline$>7$ & $107(82.31)$ & $23(17.69)$ & $130(86.67)$ \\
\hline Total & $117(78.00)$ & $33(22.00)$ & $150(100.00)$ \\
\hline
\end{tabular}

On applying Chi-square test, the Apgar score at 1 minute shows a significant correlation in the neonatal outcome (Table 7) and Apgar scores at 5 minute shows no significant correlation in neonatal outcome between the VBAC and the EmRCS group (Table 8).

Table 8: Labor outcome of TOLAC and Apgar score at 5 minute.

\begin{tabular}{|l|l|l|l|}
\hline $\begin{array}{l}\text { Apgar score } \\
\text { at } 5 \text { min. }\end{array}$ & $\mathbf{n}(\mathbf{\%})$ & $\mathbf{n}(\boldsymbol{\%})$ & $\mathbf{n}(\boldsymbol{\%})$ \\
\hline$\leq 7$ & $1(50.00)$ & $1(50.00)$ & $2(1.33)$ \\
\hline$>7$ & $116(78.38)$ & $32(21.62)$ & $148(98.67)$ \\
\hline Total & $117(78.00)$ & $33(22.00)$ & $150(100.00)$ \\
\hline
\end{tabular}

Table 9 shows that among $117(78 \%)$ cases of VBAC group, $7(46.67 \%)$ cases and among $33(22 \%)$ cases of EmRCS group, $8(53.33 \%)$ cases required NICU admission. In VBAC group, out of 7 cases most common indication for NICU admission was prematurity 4 (57.14\%) followed by jaundice $2(28.57 \%)$ and for observation 1(14.28\%). In EmRCS group out of $8 \mathrm{NICU}$ admissions, 6 (75\%) admissions were only for observation followed by jaundice $1(12.5 \%)$ and for poor
Apgar score 1 (12.5\%). A highly statistically significant association was found between labor outcome of TOLAC and NICU admission for observation $(\mathrm{P}<0.001)$ and no correlation was found for other indications of NICU admission.

Table 9: Labor outcome of TOLAC and NICU admission.

\begin{tabular}{|l|l|l|l|}
\hline NICU & VBAC & EmRCS & Total \\
admission & $\mathbf{n}(\mathbf{\%})$ & $\mathbf{n}(\mathbf{\%})$ & $\mathbf{n}(\mathbf{\%})$ \\
\hline Required & 7 & 8 & 15 \\
& $(46.67)$ & $(53.33)$ & $(10.00)$ \\
\hline Not required & 110 & 25 & 135 \\
& $(81.48)$ & $(18.52)$ & $(90.00)$ \\
\hline Total & 117 & 33 & 150 \\
& $(78.00)$ & $(22.00)$ & $(100.00)$ \\
\hline
\end{tabular}

Table 10 shows that among $117(78 \%)$ cases of VBAC group, one neonate was born asphyxiated. Vacuumassisted delivery was attempted in view of fetal distress in the $2^{\text {nd }}$ stage of labor, however, the baby was born asphyxiated and could not be revived after 5 minutes, there no bleeding per vaginum, the scar was explored, scar found intact, the cause of asphyxia was unrelated to scar rupture or previous LSCS. Among 33 (22\%) cases in EmRCS group, one baby had poor Apgar score (at $1 \mathrm{~min}$. $2 / 10$ and at $5 \mathrm{~min} .5 / 10$ ) due to uterine scar rupture. The baby was on the ventilator and died after10 days. Intraoperative uterine scar rupture was present. ( $\mathrm{P}>0.05)$ shows no significant association between neonatal mortality rates in VBAC and EmRCS group.

Table 10: Neonatal mortality in TOLAC cases.

\begin{tabular}{|c|c|c|c|}
\hline \multirow{2}{*}{$\begin{array}{l}\text { Neonatal } \\
\text { outcome }\end{array}$} & VBAC & EmRCS & Total \\
\hline & n (\%) & n (\%) & n (\%) \\
\hline $\begin{array}{l}\text { Early neonatal } \\
\text { death }\end{array}$ & $\begin{array}{l}1 \\
(100.00)\end{array}$ & $\begin{array}{l}0 \\
(0.00)\end{array}$ & $\begin{array}{l}1 \\
(0.67)\end{array}$ \\
\hline $\begin{array}{l}\text { Late neonatal } \\
\text { death }\end{array}$ & $\begin{array}{l}0 \\
(0.00)\end{array}$ & $\begin{array}{l}1 \\
(100.00)\end{array}$ & $\begin{array}{l}1 \\
(0.67)\end{array}$ \\
\hline Live births & $\begin{array}{l}116 \\
(78.38)\end{array}$ & $\begin{array}{l}32 \\
(21.62)\end{array}$ & $\begin{array}{l}148 \\
(98.66)\end{array}$ \\
\hline Total & $\begin{array}{l}117 \\
(78.00)\end{array}$ & $\begin{array}{l}33 \\
(22.00)\end{array}$ & $\begin{array}{l}150 \\
(100.00)\end{array}$ \\
\hline
\end{tabular}

\section{DISCUSSION}

The rates of cesarean section are increasing consistently worldwide; this increase needs a change in the practice. VBAC is one of the strongest modality to counter the rising cesarean section rate. The advantage of the vaginal delivery largely outweighs the risks associated with a repeat CS. Assessment of every individual case should be done and TOLAC should be offered if no contraindications for the trial of labor.

In present study, out of 150 cases for TOLAC, VBAC was successfully achieved in $117(78 \%)$ cases and (22\%) women underwent emergency LSCS, the results are 
consistent with RCOG, Zaitoun MM et al, and Tater A et al, and $70 \%$ cases with favorable Bishop Score $\geq 6,87$ $(82.86 \%)$ cases were delivered vaginally. ${ }^{6-8}$ The correlation was found statistically significant $(\mathrm{P}<0.05)$. Similar results observed by Zaitoun MM, Haresh UD et al, and Guise JM et al. .,9,10 $^{2}$

In present study, $36(24 \%)$ cases had a previous vaginal delivery (either before or after CS) had $91.67 \%$ VBAC compared to $73.69 \%$ in cases with no previous vaginal delivery. The correlation was found statistically significant $(\mathrm{P}<0.05)$. Similar results were observed by Bangal VB et al, Balachandran L et al. ${ }^{11,12}$

In present study, the most common indication for EmRCS was non-progress of labor and scar tenderness $(36.36 \%)$, consistent with Singh PS et al, and Patel RM et al. ${ }^{13,14}$ Complications were found in only $10 \%$ of the TOLAC cases, the majority of them were managed conservatively; one case of intraoperative uterine scar rupture and 2 cases of scar dehiscence were found in EmRCS group. No maternal mortality was observed in either group. The scar rupture cases $1(0.66 \%)$, consistent with the ACOG, Singh PS et al. ${ }^{1,13}$

In present study, the success rate of VBAC in, $<2.5 \mathrm{~kg}$, $2.5-3.99 \mathrm{~kg}$ and $\geq 4 \mathrm{~kg}$ birth weight group were 20 $(95.24 \%), 93(74.40 \%)$ and $4(100 \%)$ respectively. The correlation was found statistically significant $(\mathrm{P}=0.05)$. Results of present study are contradictory to other studies by Balachandran L et al, Singh PS et al, Wai-HouLi et al, in their study, birth weight was higher in the failure group. ${ }^{12,13,15}$ In present study, the indication of EmRCS was other than the birth weight in average birth weight group and in all 4 cases with $\geq 4 \mathrm{~kg}$ baby birth weight, the pelvis was assessed by senior obstetrician and trial of labor was considered.

In present study, at 1 minute, $20(13.33 \%)$ newborns had Apgar score $\leq 7$. Out of them, $10(50 \%)$ newborn were in the VBAC group and $10(50 \%)$ were in EmRCS group. The correlation was found statistically significant $(\mathrm{P}=0.003)$ at 1 minute, no statistically significant correlation was found at 5 minutes Apgar score $(\mathrm{P}=0.918)$. Wai-HouLi et al, found the Apgar scores at 1 minute and 5 minutes failed to show a difference between the VBAC group and the emergency cesarean group. ${ }^{15}$

In present study, 7 (46.67\%) cases of VBAC group and 8 $(53.33 \%)$ cases of EmRCS group required NICU admission. The most common indication for NICU admission in VBAC group was prematurity $4(57.14 \%)$ and in EmRCS group, 6 (75\%) admissions were only for observation. A highly statistically significant correlation was found for NICU admission for observation $(\mathrm{P}<0.001)$ but not significant for other indication, this shows need for NICU admission for observation is less required for VBAC as compared to EmRCS group.
Among 117 (78\%) cases of VBAC group, one neonate was born asphyxiated and could not be revived after 5 minutes, the scar was found intact, the cause of asphyxia was not related to scar rupture or previous LSCS. Among $33(22 \%)$ cases in EmRCS group, one baby had poor Apgar score due to intraoperative uterine scar rupture. The baby was on a ventilator and died after 10 days. $P$ value $>0.05$ shows no significant association. Haresh UD et al, reported perinatal mortality of $2 \% .{ }^{9}$ Balachandran L et al, reported no significant perinatal morbidity in TOLAC group. ${ }^{12}$ Singh PS et al, found 1 case of fresh stillbirth was noted due to uterine rupture. ${ }^{13}$

\section{CONCLUSION}

The trial of labor after cesarean section in carefully selected cases is of great importance in the present time due to the rising rate of primary cesarean sections. Authors conclude that TOLAC is safe and often successful in carefully selected cases, in an institution having facilities for emergency CS. Each patient should be assessed for the trial of labor and decision for the mode of delivery should be individualized. Continuous maternal and fetal monitoring should be done in these patients.

\section{Funding: No funding sources}

Conflict of interest: None declared

Ethical approval: The study was approved by the Institutional Ethics Committee

\section{REFERENCES}

1. American College of Obstetricians and Gynecologists. ACOG Practice Bulletin No. 184: Vaginal Birth After Cesarean Delivery. Obstet Gynecol 2017;130:e217-33.

2. Dweik D, Girasek E, Mészáros G, Töreki A, Keresztúri A, Pál A. Non-medical determinants of cesarean section in a medically dominated maternity system. Acta Obstet Gynecol Scand. 2014;93(10):1025-33.

3. "WHO" news release. Cesarean sections should only be performed when medically necessary. Geneva. 10 April 2015.

4. Chan A, Scott J, Nguyen A, Keane R. Pregnancy outcome in South Australia 2000. Adelaide: Pregnancy Outcome Unit, Department of Human Services; 2001.

5. Silver, RM, Landon, MB, Rouse, DJ; National Institute of Child Health and Human Development Maternal-Fetal Medicine Units Network: Maternal morbidity associated with multiple repeat cesarean deliveries. Obstet Gynecol. 2006;107:1226-32.

6. RCOG. Birth After Previous Caesarean Birth. Greentop guideline 45. Oct 2015 .

7. Zaitoun MM, Eldin SAN, Mohammad EY. A prediction score for safe and successful vaginal birth after cesarean delivery: a prospective controlled study. J Women's Health Care. 2013;2:129. 
8. Tater A, Garg S, Jawa A, Jain M. Safety and efficacy of a trial of labor after cesarean. Int $\mathrm{J}$ Reprod Contracept Obstet Gynecol. 2016;5:4335-8.

9. Haresh UD, Rohit KJ, Aarti AV. Prognostic factors for successful vaginal birth after cesarean section Analysis of 162 cases. J Obstet Gynecol India. 2010;60:498-502.

10. Guise JM, Denman MA, Emeis C, Marshall N, Walker $\mathrm{M}$, et al. Vaginal birth after cesarean: new insights on maternal and neonatal outcomes. Obstet Gynecol. 2010;115:1267-72.

11. Bangal VB, Giri PA, Shinde KK, Gavhane SP. Vaginal birth after cesarean section. North Am J Med Sci. 2013;5(2):140-4.

12. Balachandran L, Vaswani PR, Mogotlane R. Pregnancy outcome in women with previous one cesarean section. JCDR. 2014;8(2):99-102.

13. Singh PS, Bamaniya J, Shah A. Factors predicting the success of trial of labor after cesarean in the current scenario. Int $\mathbf{J}$ Reprod Contracept Obstet Gynecol. 2016;5:3893-7.

14. Patel RM, Kansara VM, Patel SK, Anand N. Impact of FLAMM scoring on cesarean section rate in previous one lower segment cesarean section patient. Int J Reprod Contracept Obstet Gynecol. 2016;5:3820-3.

15. Li WH, Yang MJ, Wang PH, Juang CM, Chang YW, Wang HI, et al. Vaginal birth after cesarean section: 10 years of experience in a tertiary medical center in Taiwan. Taiwanese J Obstet Gynecol. 2016;55(3):394-8.

Cite this article as: Beer SK, Choudhary J, Tiwari K, Choudhary S. Assessment of maternal and fetal outcome in trial of labor after cesarean. Int J Reprod Contracept Obstet Gynecol 2019;8:1563-7. 